\title{
SLMA Guidelines and Information on Vaccines
}

\author{
Fourth Edition 2011, 198 pages \\ Published by Sri Lanka Medical Association
}

Ceylon Medical Journal 2012; 57: 178

The fourth edition of the "SLMA Guidelines and Information on Vaccines", published in 2011, is an admirable effort on the part of the SLMA's Committee on Communicable Diseases to compile not merely guidelines for practical use, but an overview of the entire gamut of immunisation in Sri Lanka. The topics covered range from 'general information on vaccines' to comprehensive accounts on specific vaccines, with clearly spelt out guidelines that will be helpful in both day to day practice as well as in special clinical circumstances.

Twenty chapters on specific vaccines, arranged in alphabetical order, provide valuable information that incorporates the scientific basis for their administration, recommended schedules and dosages, efficacy and safety, indications and contraindications. Reference is made to the current epidemiological situation, taking into account local infrastructure and the logistics associated with their use. Each chapter is complete in itself, and is written in an easy to read style. The contributing authors are experts from a range of specialties. They bring to the reader upto-date information including revised guidelines.

This edition contains several new features. Particularly praiseworthy is the section on "precautions before vaccinations", of great relevance given the few, but much publicised, events in the recent past that even resulted in setbacks to otherwise excellent immunisation programmes. In this context, revised chapters on 'adverse events following immunisation' and 'management of anaphylaxis' will be of great value to the readership. Many topics have received greater attention than in previous editions. BCG vaccination in the presence of HIV infection, post exposure prophylaxis following Hepatitis A, the cold chain, new vaccines and changed indications for existing vaccines are among these.

This handy volume containing coherent, concise and clear accounts on the full gamut of immunization will undoubtedly attract a wide readership, from students to practitioners; and the SLMA deserves praise for producing it.

\section{P Senanayake ${ }^{1}$}

${ }^{1}$ Department of Paediatrics, Faculty of Medicine, University of Colombo, Sri Lanka.

Correspondence: MPS, e-mail: <manouri.senanayake@gmail.com>. Competing interests: none declared. 